\title{
Selecting a cyclic AMP kit for assaying GPCR target
}

\section{activation}

\author{
G protein-coupled receptors (GPCRs) are one of the most popular target classes investigated in the \\ drug-discovery process. With its selection of kits (cAMP femto, cAMP dynamic and cAMP HiRange), \\ Cisbio allows detection of a broad range of cyclic AMP concentrations.
}

\section{GPCR signaling pathway}

Classically, the GPCR signaling pathway is considered to be a threecomponent system that involves a seven-transmembrane-domain receptor, a trimeric G-protein complex $(\mathrm{G} \alpha, \mathrm{G} \beta, \mathrm{G} \gamma)$ and an effector. When activated, the receptor associates with the G-protein complex; this causes the exchange of GDP bound to G $\alpha$ for GTP, followed by the dissociation of G $\alpha$-GTP from the complex. The activated subunit $\mathrm{G} \alpha$ can couple to downstream effectors to regulate the amounts of second messengers. Classically, each GPCR can activate only one G protein.

After activation, GPCRs carry information within cells through two signaling pathways: regulation of cAMP level or of intracellular $\mathrm{Ca}^{2+}$, whose liberation is triggered by inositol-1,4,5-triphosphate (IP3). CAMP, calcium and IP3 are the second messengers commonly assessed to follow GPCR activation.

Drugs targeting GPCRs account for the majority of the best-selling drugs and about $40 \%$ of all prescription pharmaceuticals in the marketplace. An ever-growing interest in investigating GPCR targets in several therapeutic areas is expected, motivated by the desire to select a drug for new targets or a more selective drug targeting a specific pathway.

The assessment of cAMP with the homogeneous time-resolved fluorescence (HTRF) kits allows the implementation of functional assays to screen new drug candidates in high-throughput screening (HTS) conditions. Together with the IP-One kit for assessment of IP1, a downstream metabolite of IP3, Cisbio proposes a complete GPCR assay platform.

Here we describe the HTRF kits for cAMP detection.

\section{Functional assays: cAMP accumulation}

All Cisbio cAMP kits are based on a competitive immunoassay between native cAMP produced by cells and cAMP labeled with

\section{Jean-Luc Tardieu}

Cisbio Bioassays, BP84175, 30240 Bagnols sur Cèze Cedex, France. Correspondence should be addressed to J.-L.T. (jltardieu@cisbio.com).

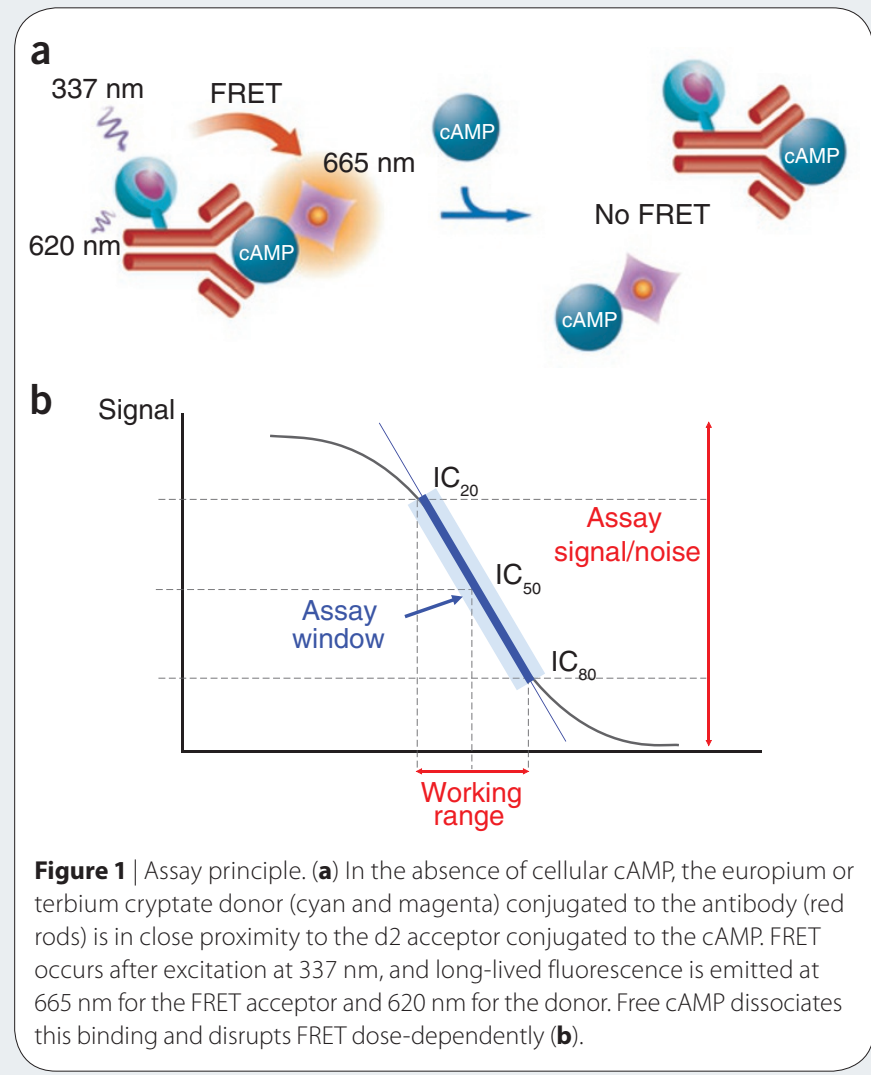

the acceptor dye $d 2$. The two entities compete for binding to a cAMP-specific antibody labeled with cryptate (europium or terbium cryptate). The specific signal generated by fluorescence resonance energy transfer (FRET) is inversely proportional to the concentration of cAMP in the standard or sample (Fig. 1a).

Intracellular cAMP level measurement facilitates early and direct pharmacological characterization of compounds acting on $\mathrm{G}_{\mathrm{i}}-$ or $\mathrm{G}_{\mathrm{s}}-$ coupled receptors. The intracellular cAMP concentration is modulated by agonist or antagonist activity at the receptor level. In a direct, homogeneous assay compatible with HTS conditions, cells expressing the target of interest are incubated with the compound. The assay 
APPLICATION NOTES

Table 1 The working range of the Cisbio's cAMP kits

\begin{tabular}{|c|c|c|c|c|}
\hline HTRF kits & HTRF cryptate & $\mathrm{IC}_{20}(\mathrm{nM})$ & $\mathrm{IC}_{50}(\mathrm{nM})$ & $\mathrm{IC}_{80}(\mathrm{nM})$ \\
\hline cAMP femto kit & Europium cryptate & \multirow{2}{*}{0.33} & \multirow{2}{*}{1.76} & \multirow{2}{*}{9.4} \\
\hline cAMP femto Tb kit & Terbium cryptate & & & \\
\hline cAMP dynamic kit & Europium cryptate & 0.91 & 4.07 & 18.1 \\
\hline cAMP HiRange kit & Europium cryptate & 4.27 & 22.8 & 121 \\
\hline
\end{tabular}

The working range is defined as the CAMP concentration between 20 and $80 \%$ inhibitory concentration $\left(\mathrm{IC}_{20}\right.$ and $\left.\mathrm{IC}_{80}\right)$. In this range, the signal variation is linearly proportional to the CAMP concentration.

compares basal cAMP in the absence of GPCR stimulation with CAMP level reached after stimulation with a drug of interest.

\section{CAMP kits to cover a broad range of assay conditions}

Cisbio offers four kits covering a broad range of working cAMP concentrations (Table 1). The kits are intended for the direct, quantitative determination of cAMP and facilitate early, direct pharmacological characterization of compounds acting on $\mathrm{G}_{\mathrm{i}}$ - or $\mathrm{G}_{\mathrm{s}}$-coupled receptors.

\section{How to select a cAMP assay}

In a cell-based assay, the intracellular cAMP level depends not only on the agonist or antagonist activity but also on the cellular model used. The technical criteria for evaluating the quality of an assay are the sensitivity, the assay signal-to-noise ratio, the working range (Fig. 1b), the robustness ( $Z^{\prime}$ factors), the miniaturization and the number of steps.

In a cell-based assay, the cAMP produced within a well determines the working range of the assay, so several biological criteria influence the selection of a cAMP assay. The cell density is different for suspension versus adherent cells and is an important parameter to optimize. The maximal cell density for adherent cells depends on the surface of the wells, which often becomes a limiting parameter in HTS. Receptor expression level and coupling efficiency for recombinant cells directly affect cAMP regulation. Measurement of $\mathrm{G}_{\mathrm{i}}{ }^{-}$
Table 2 | Effect of agonist and antagonist on the cAMP level

\begin{tabular}{llll}
\hline Drug & Mode of action & $\begin{array}{l}\text { Effect for } \mathbf{G}_{i}{ }^{-} \\
\text {coupled receptor }\end{array}$ & $\begin{array}{l}\text { Effect for } \mathbf{G}_{\mathbf{s}}{ }^{-} \\
\text {coupled receptor }\end{array}$ \\
\hline Agonist & $\begin{array}{l}\text { Produces the } \\
\text { same maximal } \\
\text { effect as the } \\
\text { endogenous } \\
\text { ligand. }\end{array}$ & $\begin{array}{l}\text { In the presence } \\
\text { of an agonist, the cAMP } \\
\text { level decreases. }{ }^{\text {a }}\end{array}$ & $\begin{array}{l}\text { In the presence } \\
\text { of an agonist, } \\
\text { the cAMP level } \\
\text { increases. }\end{array}$ \\
\hline $\begin{array}{l}\text { Antagonist } \\
\text { Blocks receptor } \\
\text { response by } \\
\begin{array}{l}\text { competing with } \\
\text { agonists or } \\
\text { inverse agonists. level increases. }\end{array}\end{array}$ & $\begin{array}{l}\text { In the presence of an } \\
\text { antagonist, the effect } \\
\text { inhibited, and the cAMP }\end{array}$ & $\begin{array}{l}\text { In the presence } \\
\text { an agonist, the } \\
\text { antagonist reduces } \\
\text { the cAMP level. }{ }^{b}\end{array}$ \\
\hline
\end{tabular}

aTo perform an agonist assay, the adenlyate cyclase must be first directly activated by a specific agent

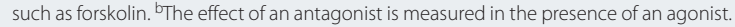

coupled receptor stimulation requires a cAMP assay capable of discriminating a slight variation of cAMP concentration; that is, having a good signal-to-noise ratio. The pharmaceutical class of drug under investigation also has a bearing on the specifications required for the CAMP assay. For antagonism assays, sensitivity is often required to detect a slight variation of cAMP concentration (Table 2).

\section{Conclusion}

Because of the variability of the biological material and the pharmacological compounds acting on $\mathrm{G}_{\mathrm{i}}$ - or $\mathrm{G}_{\mathrm{s}}$-coupled receptors, a selection of cAMP assay kits is necessary to cover a broad range of concentrations.

The homogeneous cAMP assay kits offered by Cisbio are compatible with robust ( $Z^{\prime}$ factors), miniaturized, high-throughput screens in either 384 or 1,536 wells. These cAMP accumulation assays have been applied to the investigation of $\mathrm{G}_{\mathrm{s}}$ - and $\mathrm{G}_{\mathrm{i}}$-coupled GPCRs and can be used with recombinant, nonrecombinant or native receptors.

This article was submitted to Nature Methods by a commercial organization and has not been peer reviewed. Nature Methods takes no responsibility for the accuracy or otherwise of the information provided. 